\title{
Pubertal Growth and Serum Testosterone and Estradiol Levels in Boys
}

\author{
Anna-Karin Albin ${ }^{a}$ b Ensio Norjavaara ${ }^{a}$ \\ ${ }^{a}$ Göteborg Pediatric Growth Research Center, Institute of Clinical Sciences, The Sahlgrenska Academy at the University \\ of Gothenburg, Gothenburg, and ${ }^{\mathrm{b}}$ Department of Paediatrics, Hospital of Helsingborg, Helsingborg, Sweden
}

\section{Key Words}

Testosterone · Estradiol · Puberty · Growth · Boys · Peak height velocity

\begin{abstract}
Background/Aims: To study serum testosterone and estradiol in healthy boys in relation to growth during puberty up to peak height velocity (PHV). Methods: Growth velocity was analyzed through testosterone $(n=41)$ and $17 \beta$-estradiol $(n=37)$ 24-hour profiles in a dose-response model. Participants were 26 healthy boys admitted for short or tall stature or participating as healthy volunteers at the Queen Silvia Children's Hospital. Other inclusion criteria included the following: gestational age 37-42 weeks, birth weight and length $>-2$ standard deviation score (SDS) and prepubertal height and weight within \pm 3 SDS. Testosterone was measured using a modified radioimmunoassay (RIA) with a detection limit of $0.03 \mathrm{nmol} / \mathrm{l}$. Estradiol was determined using an ultrasensitive extraction RIA with a detection limit $4 \mathrm{pmol} / \mathrm{l}$. A sixth-grade polynomial was fitted to each child's growth data, giving growth velocity and age at PHV. Results: Growth velocity increased by $50 \%$ from prepubertal growth to PHV at a morning testosterone level of $3.1 \mathrm{nmol} / \mathrm{l}(95 \%$ confidence interval 2.4-4.2), $\mathrm{EC}_{50}$. The corresponding $\mathrm{EC}_{50}$ of $17 \beta$-estradiol was $6.5 \mathrm{pmol} / \mathrm{I}$ (3.2-13). Boys approaching PHV
\end{abstract}

( $<4 \%$ remaining) had morning testosterone levels $>10 \mathrm{nmol} / \mathrm{I}$ and $17 \beta$-estradiol $>9 \mathrm{pmol} / \mathrm{l}$. Conclusion: Observed early puberty/initial mid puberty morning testosterone levels of 2.4$4.2 \mathrm{nmol} / \mathrm{l}$ are associated with a $50 \%$ increase in growth velocity from prepubertal growth to PHV in healthy boys.

Copyright $\odot 2013$ S. Karger AG, Basel

\section{Introduction}

The influence of androgens and estrogens on growth is complex, as these steroids can have both a direct effect on bone growth and an indirect effect on longitudinal growth via an effect on growth hormone $(\mathrm{GH})$ secretion [1]. The role of androgens and estrogens in human growth is mainly based on studies of disease in steroidogenesis or steroid receptor mutations. Estrogen deficiency resulting from mutations in the aromatase gene [2] and estrogen resistance caused by mutation in the estrogen receptoralpha (ER- $\alpha$ ) gene [3] lead to continued longitudinal bone growth into adulthood. At the other extreme is the complete androgen insensitivity syndrome, characterized by a pubertal growth spurt with a timing and magnitude resembling that of normal women and a final height greater than that of normal women $(+1.4 \mathrm{SD})$ but less than that in normal men (-0.6 SD) [4].

\begin{tabular}{|c|c|}
\hline KARGER & $\begin{array}{l}\text { (c) } 2013 \text { S. Karger AG, Basel } \\
1663-2818 / 13 / 0802-0100 \$ 38.00 / 0\end{array}$ \\
\hline $\begin{array}{l}\text { E-Mail karger@karger.com } \\
\text { www.karger.com/hrp }\end{array}$ & $\begin{array}{l}\text { This is an Open Access article licensed under the terms of the } \\
\text { Creative Commons Attribution-NonCommercial 3.0 Un- } \\
\text { ported license (CC BY-NC) (www.karger.com/OA-license), } \\
\text { applicable to the online version of the article only. Distribu- } \\
\text { tion permitted for non-commercial purposes only. }\end{array}$ \\
\hline
\end{tabular}

Anna-Karin Albin, MD

Department of Paediatrics

Hospital of Helsingborg

SE-251 87 Helsingborg (Sweden)

E-Mail anna-karin.albin@skane.se tion permitted for non-commercial purposes only. 
Nonaromitazable androgens such as DHT and oxandrolone can increase growth velocity in boys with delayed puberty and in girls with Turner syndrome, possibly via a direct stimulating effect on the growth plate, as the effect of androgens on GH secretion is mediated through estrogens both in girls and boys $[1,5]$. Estrogens have a similar effect on growth in boys and girls in the pubertal growth spurt and are also important in terminating linear growth. In girls, the start of the pubertal growth spurt precedes breast development and suggests that the increase in growth starts at lower levels of estradiol compared to the levels needed for the development of secondary sexual characteristics [6]. Boys reach their peak height velocity (PHV) on average nearly 2 years later than girls, although the boys' genitalia begin to develop only about 6 months later than girls' breast development [7]. The levels of estradiol are significantly higher in prepubertal girls compared to prepubertal boys, which could explain the differences in age of pubertal onset and epiphyseal maturation [8-11]. The association between testosterone and estradiol levels and pubertal growth is not fully understood. Increased knowledge of the relationship between sex steroids and pubertal growth is important to be able to optimize the treatment of children with various growth and puberty disorders. For example, it would be possible to start pubertal hormone replacement therapy in children with hypophyseal insufficiency without negative impact on growth at the same age as their peers enter puberty.

To evaluate sex steroids in children, high specificity and sensitivity of the analytical methods are needed. Androgen levels throughout puberty and the diurnal variation in boys are well described [12-16]. In the lab at the Göteborg Pediatric Growth Research Center (GPGRC) at Queen Silvia Children's Hospital in Gothenburg, Sweden, a sensitive modified radioimmunoassay (RIA) with an assay sensitivity of $0.03 \mathrm{nmol} / \mathrm{l}$ is used to determine concentrations of serum testosterone [15]. This method detects testosterone levels in prepubertal and pubertal children with the same accuracy as liquid chromatography tandem mass spectrometry [17]. However, determination of levels of $17 \beta$-estradiol in boys is often limited by the sensitivity of available assays or lack of specificity. It is well established that direct immunoassays do not perform well in measuring low concentrations of estradiol [18-21]. In this study we use a validated ultrasensitive extraction RIA designed for measuring low $17 \beta$-estradiol concentrations; this RIA has been in use for almost 2 decades and includes reference values for $17 \beta$-estradiol in different pubertal stages $[20,22]$. This method has a detection limit of $4 \mathrm{pmol} / \mathrm{l}$ and has been shown to distinguish prepubertal values from early pubertal values $[20,22]$.

We hypothesized that the low levels of testosterone seen in early and initial mid puberty in boys are associated with increased growth. The primary objective of the study was to determine the relationship of testosterone levels to growth and the secondary objective was to determine the relationship of estradiol levels to growth during the pubertal growth spurt up to PHV by determining the sex steroid levels associated with a 50\% increase in prepubertal growth velocity up to PHV.

\section{Subjects and Methods}

\section{Study Group}

A total of 26 healthy boys born between 1972 and 1984 participated in this study; they had been referred due to short $(n=15)$ or tall $(n=3)$ stature or had been recruited previously as healthy volunteers $(n=8)$ in studies at the GP-GRC at the Queen Silvia Children's Hospital in Gothenburg, Sweden. Boys born small for gestational age ( $<2 \mathrm{SD}$ of birth weight and height) were excluded. None of the boys had been treated with GH, and short boys with GH deficiency were excluded, based on 24-hour GH measurement or on the results of an arginine insulin tolerance test. At least one 24 -hour profile of testosterone and $17 \beta$-estradiol was assessed in each boy, although some boys had multiple 24-hour profiles of both testosterone and $17 \beta$-estradiol [testosterone: $2(\mathrm{n}=4), 3(\mathrm{n}=$ $2), 4(\mathrm{n}=1), 6(\mathrm{n}=1) ; 17 \beta$-estradiol: $2(\mathrm{n}=3), 3(\mathrm{n}=1), 5(\mathrm{n}=2)]$. Profiles of 24 -hour testosterone and $17 \beta$-estradiol were analyzed from prepuberty up to 3 months after age at PHV. The $17 \beta$-estradiol and testosterone profiles of some of the participants have been published elsewhere $[12,15,22]$.

Growth data were collected from child healthcare centers, school health services and the GP-GRC. Boys with prepubertal growth consistently beyond the range \pm 3 standard deviation score (SDS) in height or weight according to Swedish growth reference values for healthy children were excluded [23]. Pubic hair development was assessed according to Tanner [24] and testicular volumes were determined by orchidometer [25]. Bone age was measured and was evaluated by the same radiologist at the Queen Silvia Children's Hospital in Gothenburg, Sweden, according to Tanner-Whitehouse 2 [26]. Assent was obtained from the boys and written informed consent was obtained from their parents for future analysis of these data. The Regional Ethics Committee at Sahlgrenska Academy at the University of Gothenburg approved the research protocol. Demographic and auxiliary parameters for the boys in the study group are shown in table 1.

\section{Study Design}

Blood Sampling

In the 26 boys, a total of forty-one 24-hour serum profiles of sex steroids were obtained. In the steroid analysis, testosterone was prioritized and only 37 profiles of $17 \beta$-estradiol were obtained. The boys stayed in hospital for 2 days for each serum pro- 
Table 1. Demographic and auxiliary parameters at time of 24-hour sex steroid profile for all boys

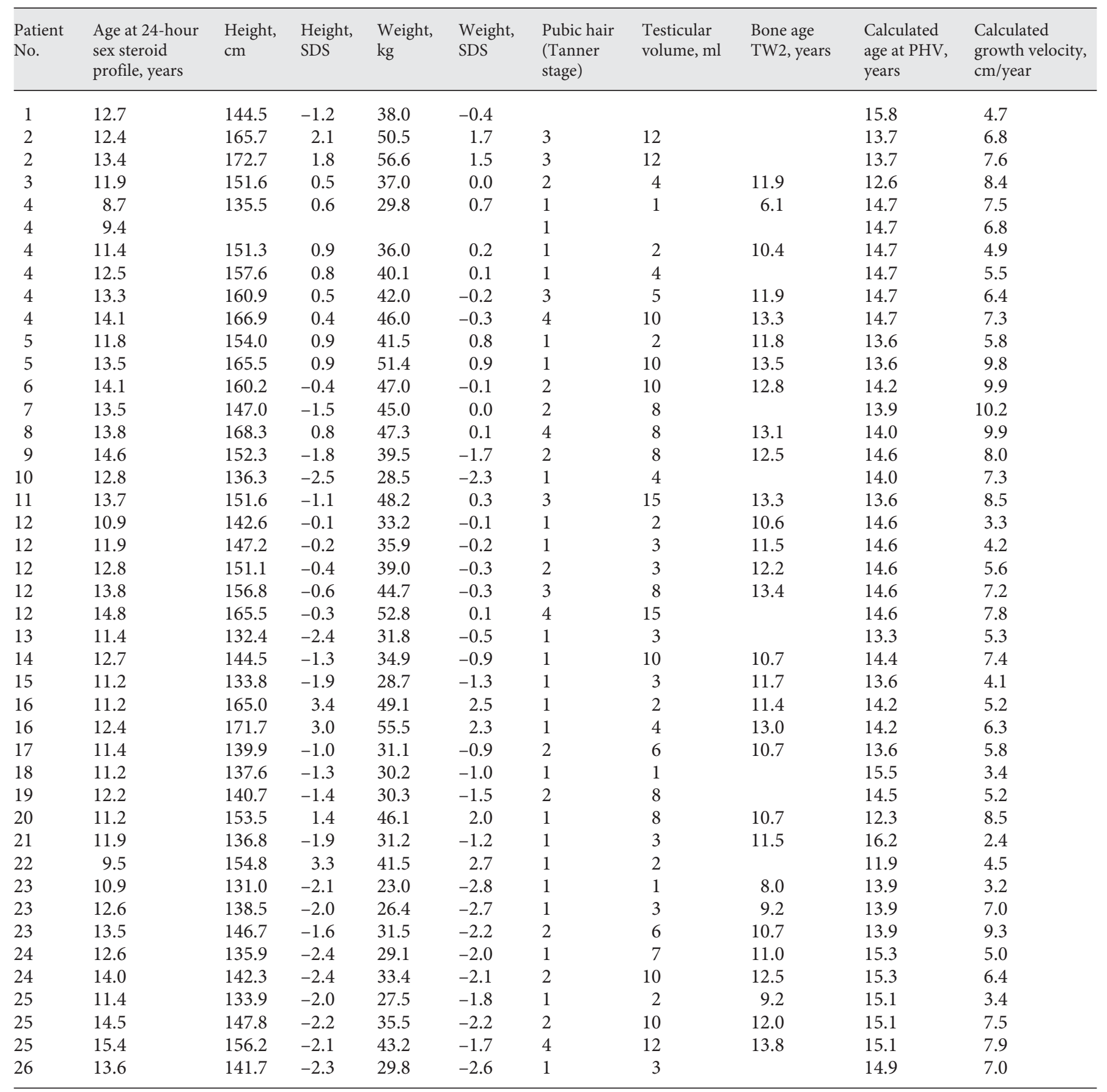

TW2 = Tanner-Whitehouse 2 .

file. The first morning or evening, a heparinized needle was inserted and blood for testosterone and estradiol measurements was taken at 10:00, 14:00, 18:00, 22:00, 02:00, 04:00, 06:00 and 10:00 h. The serum samples were centrifuged and stored at $-20^{\circ} \mathrm{C}$ until assayed.
Hormonal Measurements

Testosterone Measurement. Serum testosterone levels were determined in duplicate using a modified RIA (Spectria testosterone RIA; Orion Diagnostica, Espoo, Finland), as described elsewhere [15]. The detection limit was $0.03 \mathrm{nmol} / \mathrm{l}(0.86 \mathrm{ng} / \mathrm{dl})$. 


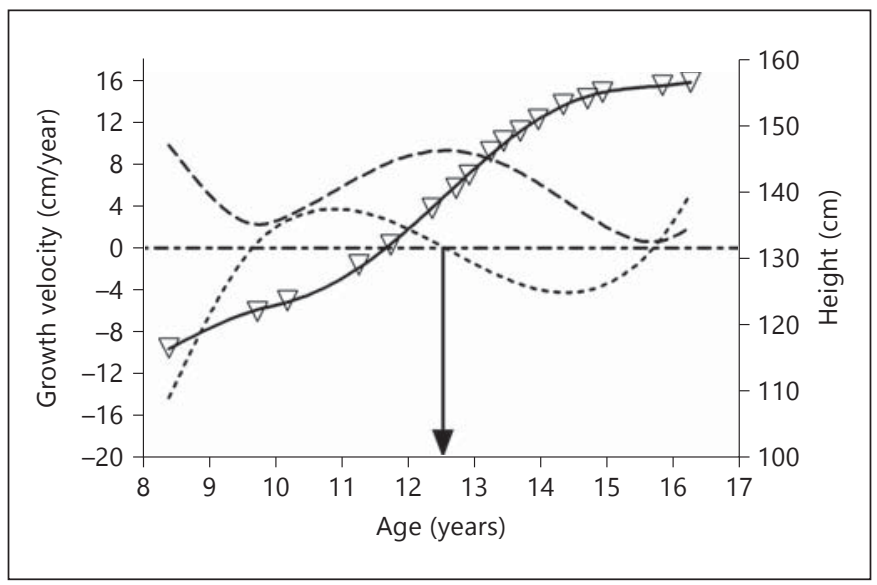

Fig. 1. The figure demonstrates the calculation of growth velocity and age at PHV. One boy's height records $(\nabla)$ are shown with the fitted 6 th grade polynomial (solid line). The first derivative of the 6 th grade polynomial (dashed line) equals the height velocity. The arrow is a marker of when the second derivative (dotted line) equals 0 , which is the age of $\mathrm{PHV}$.

$17 \beta$-Estradiol Measurement. Serum $17 \beta$-estradiol concentrations were quantified using an accredited modified extraction RIA (Spectria E2, ORION Diagnostica, Espoo, Finland) with a detection limit of $4 \mathrm{pmol} / \mathrm{l}(1 \mathrm{pg} / \mathrm{ml})$, as described elsewhere [20, 22, 27].

Growth Velocity Measurements

Calculating growth velocity using height difference over time is a method that is highly sensitive to height measurement errors and will give a wide variation of results. In this study, a sixth-grade polynomial was fitted to each boy's growth data from the pubertal growth spurt up to PHV. Aiming for the best possible fit of the polynomial to the boy's growth around the age when sex steroids were obtained, the number of height measurements used to fit the polynomial to the growth data ranged from 6 to 32 (mean 12.9, median 11.0). Calculated height values through the polynomial fit were compared with measured height using a Bland-Altman plot [28]. Measured height and calculated height values were similar; the bias (difference between the means) was $0.00091 \mathrm{~cm} \pm 0.44 \mathrm{SD}$. The derivative of the fitted sixth-grade polynomial was used to calculate growth velocity at each time point. The second derivative of the sixth-grade polynomial was used to calculate age at PHV. The age at PHV was determined as the time point where the second derivative is zero. The PHV is reached when the second derivative passes through zero and changes from + to -. In figure 1, this is illustrated for 1 boy. This way of treating growth data generates growth velocity values for each time point, including at PHV. Most of the boys were followed through puberty up to final height. The boys with missing data for final height were all followed until growth velocity had clearly leveled off, enabling us to perform these calculations.

The growth data were collected from GP-GRC, schools and child health services and thus could be of varying quality. However, the most valuable records for the calculations reported here the growth data around the time point when the sex steroid profiles were obtained - were all measured at GP-GRC by experienced staff. Each growth chart was checked manually for obvious measurement errors by a pediatric endocrinologist (E.N.) who also assessed whether the calculated PHV and age at PHV were reasonable, controlling for overfitting.

Pubertal Growth Patterns

A variety of growth patterns was seen among the boys, whose prepubertal growth ranged from -3 to $+3 \mathrm{SD}$. The prepubertal and pubertal growth velocity of tall boys was higher than in short and normal-stature boys. However, the growth of tall, normal and short boys was analyzed in relation to their PHV as a ratio, on the assumption that this was similar for all boys. This would allow us to use all boys in the same study population regardless of their prepubertal growth. In figure 2, each boy's growth velocity is expressed as a ratio of PHV at time points every 3 months, from 2.5 years before age at PHV to 6 months after age at PHV. The short boys (prepubertal growth $<-2$ but $>-3$ height SDS) and tall boys (prepubertal growth $>2$ but $<3$ height SDS) did not differ from the boys with normal stature. The shaded area in figure 2 shows the $95 \%$ confidence interval $(\mathrm{CI})$ of the mean of the normal-stature boys, which covers the means of both the short and the tall boys.

\section{Pubertal Growth Ratio}

According to Karlberg's ICP model, the pubertal growth component is similar across children, independent of stature, but the combination of differences in the childhood component (prepubertal) and the constant pubertal component results in different growth velocity during puberty between short and tall children. To be able to study the association between sex steroids and growth during the pubertal spurt from prepuberty up to PHV, a pubertal growth ratio was created. The growth velocity at the age when the 24 -hour $17 \beta$-sex steroid profile was obtained was expressed as a ratio of $\mathrm{PHV}$, adjusted for prepubertal growth [ growth velocity at the age when the 24-hour sex steroid profile was obtained minus prepubertal growth velocity)/(PHV minus prepubertal growth velocity)]. Using the pubertal growth ratio enables us to study the pubertal growth component independent of stature. This ratio was applied to detect any dose-response relationship between sex steroids and growth. In this way, the maximum effect, $\mathrm{PHV}$, corresponds to a pubertal growth ratio value of 1 and the ratio is 0 before puberty starts. We set the age of prepubertal growth to 2.5 years before the age at PHV to be sure that the time period studied covered prepubertal growth.

\section{Statistical Analysis}

The standard statistical package SPSS, v.17.0 (SPSS Inc., Chicago, Ill., USA) was used to perform statistical analyses, together with GraphPad Prism, v.5.03 (GraphPad Software Inc., http://www. graphpad.com) and WinNonlin, v.4.1 (Pharsight, St Louis, Mo., USA).

To find the individual sixth-grade polynomial fitting the growth data for each boy, the statistical program SAS, v.8.1 (SAS Institute Inc., Cary, N.C., USA) was used. Age at PHV was calculated by solving the second derivative of the sixth-grade polynomial using Deadline software, v.2.31 (http://deadline.3x.ro/).

Bland-Altman analysis [28] was used to compare measured and calculated heights. In statistical analyses and figures, values of estradiol below the detection limits were set to the expected value of $2 \mathrm{pmol} / \mathrm{l}$ (the detection limit divided by 2 ). 
Fig. 2. Comparison of individual growth patterns for boys of short, tall and normal stature. Scatterplot of the ratio of growth velocity/PHV at different time points from the age at PHV for boys who were short (prepubertal height $<-2$ but $>-3 \mathrm{SD}$ ), normal (prepubertal height within \pm 2 SD) and tall (prepubertal height $>2$ but $<3$ SD). The time points are set to every 3 months from 2.5 years before the age at PHV until 6 months after PHV. Interpolation lines represent data for individual boys in the different groups and the mean of all boys with short, tall or normal stature. The mean for boys of normal stature is shown with a shaded area indicating the 95\% CI, which includes the means of the tall and short boys. $\boldsymbol{\nabla}=$ Normal; $\nabla=$ short; $\mathrm{O}=$ tall.

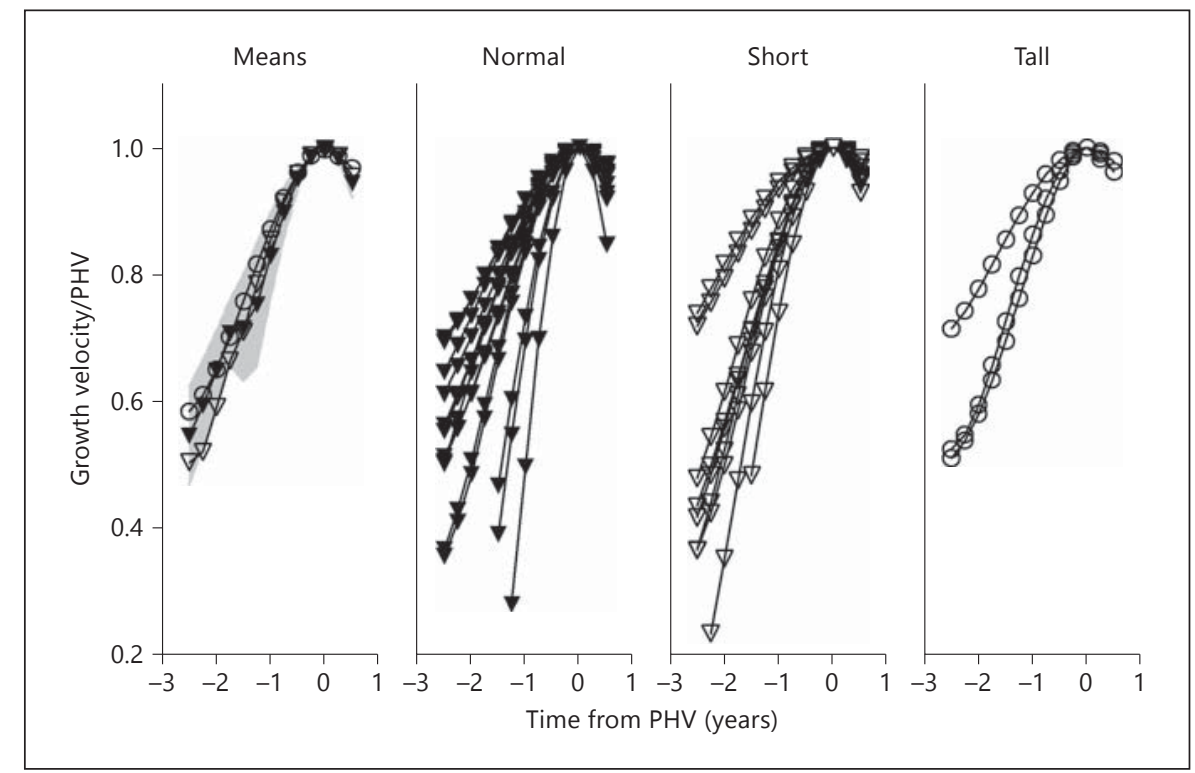

Testosterone is secreted with a diurnal pattern in boys during both prepuberty and puberty, with the nadir in the evening and the highest levels found in the morning around 06:00 $\mathrm{h}$ [15]. Morning testosterone was thereby defined as the value of testosterone obtained from blood samples drawn at 06:00 h. If this value was missing, the value at 04:00 $\mathrm{h}$ was used.

The diurnal pattern of $17 \beta$-estradiol seen in early puberty in girls is not seen in boys until they reach mid puberty [22]. The highest values are seen earlier in the morning in boys (around 06:00 h) compared to girls (around 10:00 h) [22, 27]. Morning $17 \beta$-estradiol was thus defined as the value of estradiol obtained from blood samples drawn at 06:00 h. If the value at 06:00 h was missing, the value at 04:00 h was used.

As the serum testosterone and estradiol levels were not normally distributed, linear and nonlinear regression analyses were performed on log-transformed data.

Results are expressed as mean (SD) or median (range) unless otherwise stated. $\mathrm{p}<0.05$ was considered significant.

Linear regression and nonlinear regression analyses (a dose-response model) were used to calculate the value of sex steroid that will respond to $50 \%$ of the pubertal growth ratio, $\mathrm{EC}_{50}$. The results are expressed as $\mathrm{EC}_{50}$ with a $95 \% \mathrm{CI}$. A simple Emax model in WinNonlin was also used to find the $\mathrm{EC}_{50}$ value; the analysis was made on nonlog-transformed data with results expressed as $\mathrm{EC}_{50} \pm \mathrm{SD}$.

In boys with repeated measurements of estradiol and testosterone, the last measurement was included in the correlation analyses and calculations of $\mathrm{EC}_{50}$.

\section{Results}

\section{Anthropometric Data}

Table 1 shows the descriptive anthropometric data of the study population.
The mean model fit calculated PHV was $8.7 \mathrm{~cm} /$ year $( \pm 1.2)$ for all boys in the study group. The mean age at PHV was 14.3 years $( \pm 0.85)$, which is 0.8 years later than a Swedish reference population born in 1974 (13.5 years $\pm 1.03 \mathrm{SD}$ ) [29], but this later average onset of $\mathrm{PHV}$ is largely explained by the fact that the short boys in the present study had a mean age at PHV of 14.6 years $( \pm 0.82)$. There were 5 boys with both 24 -hour sex steroid profiles and bone age measurements \pm 3 months from the age at PHV. Their mean chronological age was 13.8 years $( \pm 0.44)$, their bone age was 13.0 years $( \pm 0.40)$ and their median testicular volume was $10 \mathrm{ml}$ $(8-15)$.

\section{Growth Velocity and Time to PHV}

Figure 3a shows growth velocity and time from 24hour sex steroid profile to PHV. The 6 boys with 24 -hour sex steroid profiles within \pm 3 months from PHV had a mean growth velocity of $8.95 \mathrm{~cm} /$ year $( \pm 0.99)$ and the 11 boys with 24 -hour sex steroid profiles in prepuberty had a mean growth velocity of $4.5 \mathrm{~cm} /$ year $( \pm 1.6)$.

\section{Testosterone and Time to PHV}

Figure $3 \mathrm{~b}$ shows morning testosterone and time from 24-hour testosterone profile to PHV. The median morning testosterone of the 6 boys with 24-hour profiles within \pm 3 months from PHV was $11.4 \mathrm{nmol} / \mathrm{l}$ (713 ), and the 10 boys with 24 -hour profiles in prepuberty had a median morning testosterone of $0.25 \mathrm{nmol} / \mathrm{l}$ $(0-1)$. 


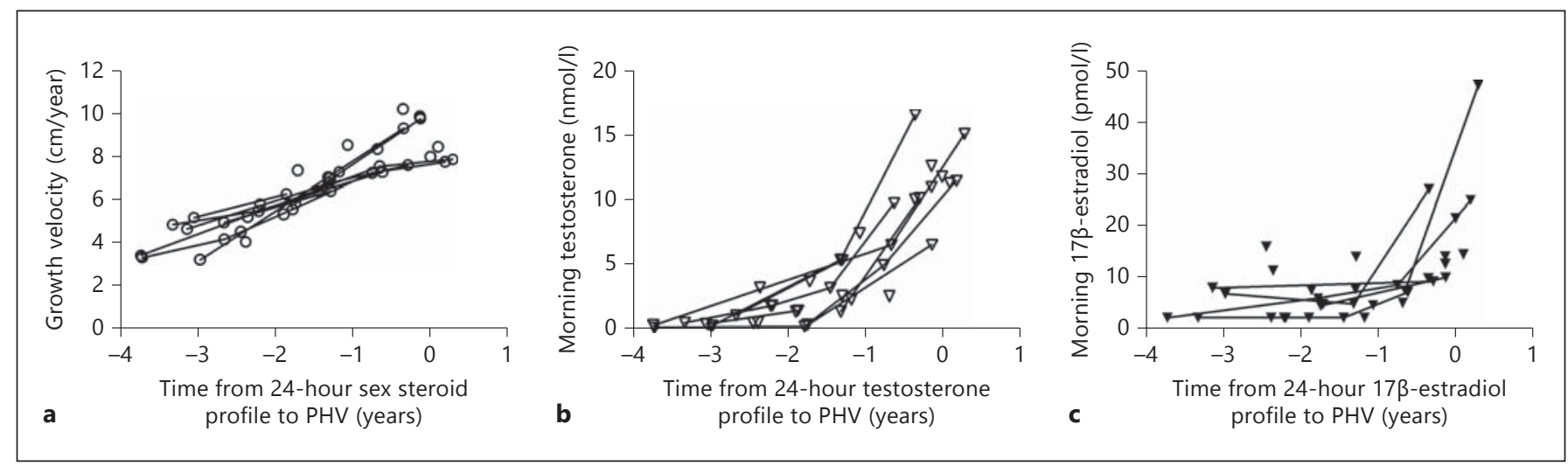

Fig. 3. Descriptive scatterplots of growth velocity at the time of investigation (24-hour sex steroid profile) in relation to remaining time to PHV (a), morning testosterone at the time of investigation in relation to remaining time to $\mathrm{PHV}(\mathbf{b})$ and morning $17 \beta$-estradiol at the time of investigation in relation to remaining time to $\mathrm{PHV}(\mathbf{c}) . \mathrm{O}=$ Growth velocity; $\nabla=$ morning testosterone; $\nabla=$ morning $17 \beta$-estradiol.

\section{$17 \beta$-Estradiol and Time to $\mathrm{PHV}$}

Figure $3 c$ shows morning $17 \beta$-estradiol and time from 24 -hour $17 \beta$-estradiol profile to PHV. Around PHV, the median morning estradiol was $14.2 \mathrm{pmol} / \mathrm{l}$ (9.9-24.8, $\mathrm{n}=6$ ). The median of the medians of the 24 -hour $17 \beta$ estradiol profiles was $9.8 \mathrm{pmol} / \mathrm{l}(7-13, \mathrm{n}=6)$ around PHV. In prepuberty, the median morning $17 \beta$-estradiol was $2 \mathrm{pmol} / \mathrm{l}(2-7.9, \mathrm{n}=7)$ and the median of the medians of the 24 -hour $17 \beta$-estradiol profiles was $2 \mathrm{pmol} / \mathrm{l}$ $(2-9.9, \mathrm{n}=9)$.

\section{Relation between Testosterone and Estradiol}

There was a strong association between morning testosterone and morning estradiol levels $\left(\mathrm{r}^{2}=0.64, \mathrm{p}<\right.$ 0.0001 ) among boys with testicular volume from $3 \mathrm{ml}$. The strongest correlation and the steepest regression line was seen in boys in whom sex steroids were obtained less than 6 months before PHV $(\mathrm{r}=0.73, \mathrm{p}<0.05)$. In boys with testicular volumes from $3 \mathrm{ml}$ but more than 0.5 years remaining to $\mathrm{PHV}$, the association was slightly weaker $(\mathrm{r}=0.61, \mathrm{p}<0.05$; fig. 4$)$.

\section{Testosterone and Growth Velocity}

A positive correlation was found between morning testosterone and growth velocity at the time when the 24hour profile was obtained $(\mathrm{r}=0.88, \mathrm{p}<0.001)$. When dividing the boys into groups according to their testicular volumes the strongest correlation was seen in boys with testicular volumes between 3 and $6 \mathrm{ml}(\mathrm{r}=0.87, \mathrm{p}<$ 0.001 ). In boys with testicular volumes above $6 \mathrm{ml}$ the association was weaker $(\mathrm{r}=0.56, \mathrm{p}<0.05)$. There was no significant correlation between growth velocity and

Sex Steroids and Pubertal Growth in Boys

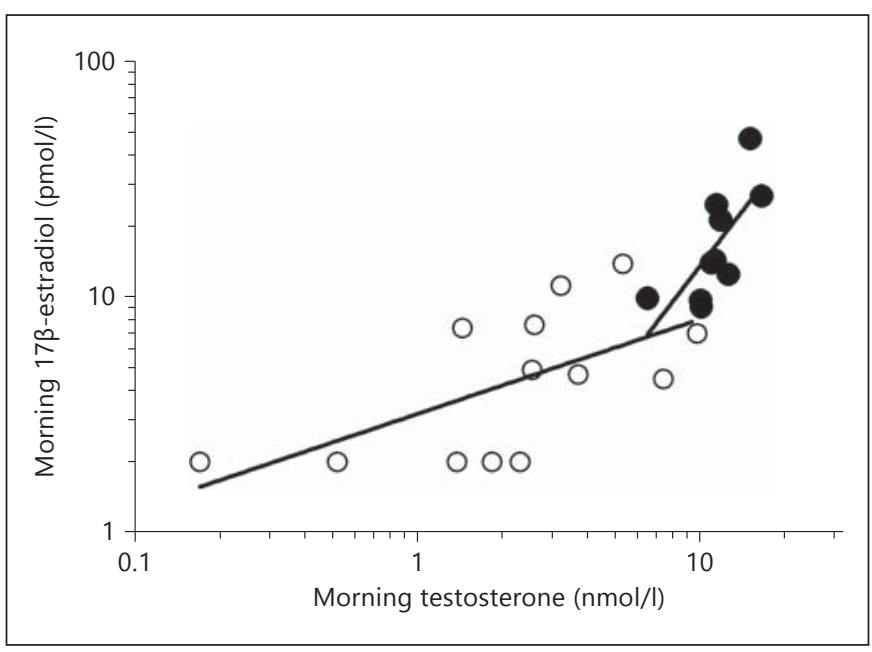

Fig. 4. Linear regression analyses between serum testosterone and estradiol levels in boys with testicular volumes from $3 \mathrm{ml}$. The steepest regression line was found in boys with sex steroids obtained closer to PHV $(\mathrm{r}=0.73, \mathrm{p}<0.05)$. In boys with more than 6 months remaining to $\mathrm{PHV}$, the correlation was $\mathrm{r}=0.61, \mathrm{p}<0.05$. $0=<6$ months to PHV; O = >6 months to PHV.

morning testosterone in boys with testicular volume $<3 \mathrm{ml}$. The relation between growth velocity and morning testosterone in boys with different testicular volumes is shown in figure 5. Taking into consideration the different growth patterns of the boys, the pubertal growth ratio was analyzed in relation to early morning testosterone. In 4 boys it was not possible to calculate their prepubertal growth velocity correctly using the fitted sixthgrade polynomial. These 4 boys were excluded from the 


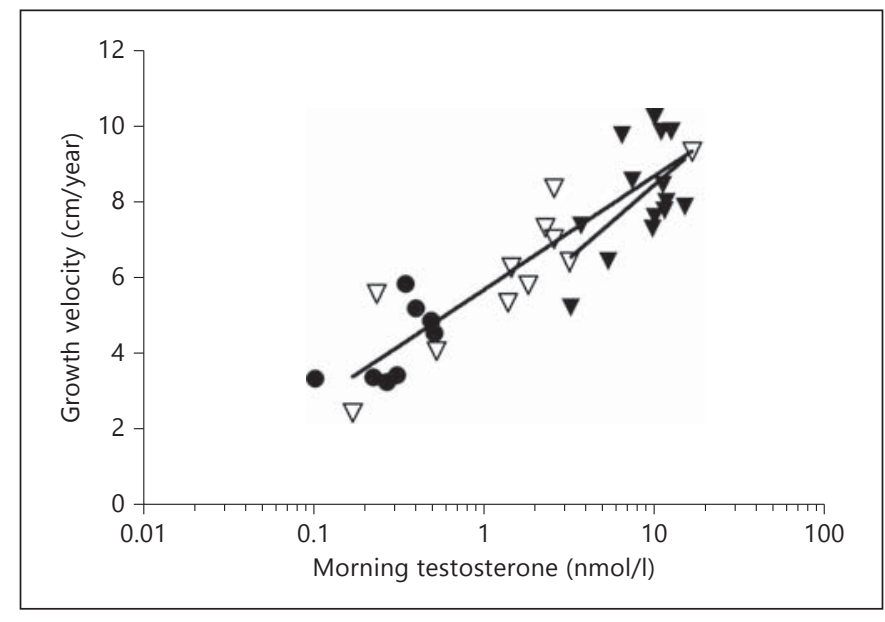

Fig. 5. Linear regression analyses between morning testosterone and growth velocity. Significant correlation was seen in boys with testicular volumes of 3-6 ml $(\mathrm{r}=0.87, \mathrm{p}<0.001)$ and testicular volumes $>6 \mathrm{ml}(\mathrm{r}=0.56, \mathrm{p}<0.05) . \bullet=<3 \mathrm{ml} ; \nabla=3-6 \mathrm{ml} ; \boldsymbol{\nabla}=>6 \mathrm{ml}$.

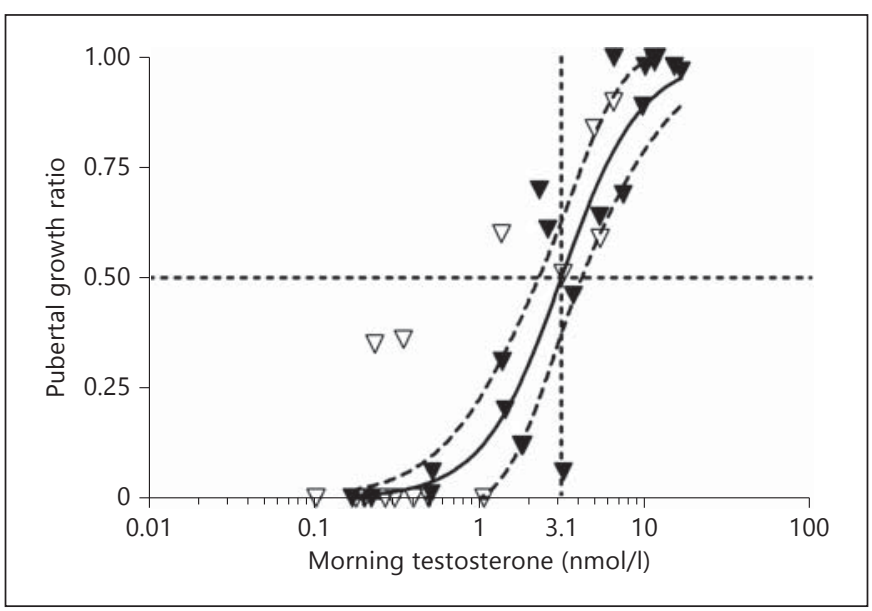

Fig. 6. Nonlinear regression analyses between morning testosterone and the constructed pubertal growth ratio (growth velocity at time of obtained sex steroid/PHV, adjusted for prepubertal growth velocity). The pubertal growth ratio is 0 before puberty starts and 1 at the time of PHV. The calculated $\mathrm{EC}_{50}$ with the $95 \% \mathrm{CI}$ from the dose-response model is shown. In boys followed longitudinally with multiple measurements, the last measurement was chosen for the analyses, although all data are shown in the figure. $\boldsymbol{\nabla}=$ Last measurement; $\nabla=$ all data.

pubertal growth ratio analysis because the fitting process excluded the growth data close to start of puberty in favor of the best possible fit of the polynomial to the growth data in the time period when 24 -hour sex steroid profiles were obtained.
The calculated $\mathrm{EC}_{50}$ value of morning testosterone corresponding to a $50 \%$ increase in the pubertal growth ratio was $3.1 \mathrm{nmol} / 1\left(2.4-4.2, \mathrm{r}^{2}=0.84\right)$ using the dose-response model (fig. 6). A similar level of testosterone was found using linear regression: $2.5 \mathrm{nmol} / \mathrm{l}\left(1.8-3.5, \mathrm{r}^{2}=0.81\right)$. Using the third method, the simple Emax model, to calculate an $\mathrm{EC}_{50}$ value, the result was $3.1 \mathrm{nmol} / \mathrm{l}( \pm 0.9 \mathrm{SD})$. The results of the different methods of calculating the $\mathrm{EC}_{50}$ value were comparable. It was possible to calculate an individual $\mathrm{EC}_{50}$ for 1 of the boys with 6 measurements of testosterone and this was close to the value for the whole group: $3.3 \mathrm{nmol} / \mathrm{l}$ (2.8-3.9), using the dose-response model.

All boys $>10 \mathrm{nmol} / \mathrm{l}(\mathrm{n}=6)$ had reached $96 \%$ of their pubertal growth ratio and were close to PHV; 1 boy with morning testosterone $<10 \mathrm{nmol} / \mathrm{l}(6.5 \mathrm{nmol} / \mathrm{l})$ was also close to PHV; 11 of 12 boys with testosterone $>6 \mathrm{nmol} / \mathrm{l}$ had testicular volumes of $\geq 8 \mathrm{ml}$.

The mean age of the boys with morning testosterone levels between 2.4 and $4.2 \mathrm{nmol} / \mathrm{l}$ was 12.7 years $( \pm 0.7)$ and their mean age at PHV was 14.2 years $( \pm 0.9)$, with a mean age difference of 1.5 years $( \pm 0.6)$ between the age when serum testosterone was obtained and the age at PHV.

\section{Estradiol and Growth Velocity}

The morning $17 \beta$-estradiol was positively correlated with growth velocity at the time when the 24-hour $17 \beta$-estradiol profile was obtained $(\mathrm{r}=0.54, \mathrm{p}<0.05)$. When excluding the prepubertal boys, the correlation was marginally stronger $(\mathrm{r}=0.58, \mathrm{p}<0.05)$. For boys with testicular volumes between 3 and $6 \mathrm{ml}$, there was a correlation of $\mathrm{r}=0.65, \mathrm{p}<0.05$, but there was no significant correlation between morning estradiol and growth velocity in boys with testicular volumes $>6 \mathrm{ml}$.

The pubertal growth ratio created was analyzed relative to morning estradiol with the same procedure as was performed with testosterone.

The calculated $\mathrm{EC}_{50}$ value of morning estradiol corresponding to a $50 \%$ increase in the pubertal growth ratio was $6.5 \mathrm{pmol} / \mathrm{l}(3.2-13)$ using the dose-response model (online suppl. fig. 1; for all online suppl. material, see www.karger.com/doi/10.1159/000353761). Using linear regression, the $\mathrm{EC}_{50}$ value was 6.4 (2.6-13.3). However, the scatter of estradiol levels was wide and the goodnessof-fit was $r^{2}=0.34$ using the dose-response model and $\mathrm{r}^{2}=0.35$ using linear regression.

The simple effect max model in WinNonlin calculated an $\mathrm{EC}_{50}$ of $6.4 \mathrm{pmol} / \mathrm{l}( \pm 5.3 \mathrm{SD})$.

A total of 7 of 10 boys with $17 \beta$-estradiol $>9 \mathrm{pmol} / \mathrm{l} \mathrm{had}$ $<4 \%$ remaining of their growth up to PHV; 8 of the 10 boys had a testicular volume $\geq 8 \mathrm{ml}$. 
The mean age of the boys with morning estradiol levels between 3.2 and $13 \mathrm{pmol} / \mathrm{l}$ was 12.9 years $( \pm 1.0)$ and their mean age at PHV was 14.1 years $( \pm 0.8)$ with a mean age difference of 1.3 years $( \pm 0.9)$ between the age when serum estradiol was obtained and the age at PHV.

\section{Discussion}

The present study is unique in providing findings on the detailed association between testosterone, estradiol and increased growth during puberty up to PHV in boys. The testosterone values in this study fit well into the pattern of a dose-response relationship with increased growth velocity up to PHV during puberty, and the calculated $\mathrm{EC}_{50}$ value of testosterone, $3.1 \mathrm{nmol} / \mathrm{l}$ (2.4-4.2), corresponds to the low morning testosterone values seen in the transition from early to mid puberty [15]. The mean age of the boys in this study with serum testosterone levels between 2 and $4 \mathrm{nmol} / \mathrm{l}$ was $12.7 \pm$ 0.7 years, which is approximately 1.5 years ahead of the timing of their PHV. In a study by Klein et al. [30] in 1996, the level of testosterone 1 year before PHV was approximately $10 \mathrm{nmol} / \mathrm{l}$, which is the level we found in boys closer to PHV. The differences in our results could of course be due to differences in methods of calculating growth velocity but might also reflect differences in the testosterone assays used. The boys in our study with morning testosterone exceeding $10 \mathrm{nmol} / \mathrm{l}$ were all close to PHV and had testicular volumes $\geq 8 \mathrm{ml}$, which is in line with findings that pubertal boys reach PHV when their testicular volumes are about $10-12 \mathrm{ml}$ $[15,31-33]$.

In boys with testicular volumes between 3 and $6 \mathrm{ml}$ there was a correlation between serum testosterone values and increased growth velocity, but the correlation was lower in boys with testicular volumes $>6 \mathrm{ml}$. One possible explanation for the decrease in association when testicular volume exceeds $6 \mathrm{ml}$ is that the remaining increase in growth velocity up to PHV is small but the increase in testosterone is still large. Of special interest in this context is that peak GH secretion occurs close to PHV in Tanner genital stage 4 in boys [34]; given that growth velocity in this time period is correlated to a higher degree with GH secretion, this could be a contributing factor in the weak correlation between testosterone, estradiol and growth velocity in boys closer to PHV. A third possibility is that testosterone/estrogen accelerates the normal process of growth plate senescence, exhaustion and fusion [35]. The process of proliferation starts before

Sex Steroids and Pubertal Growth in Boys testicular volume reaches $6 \mathrm{ml}$ and part of the remaining proliferation process continues independently of steroids, while other parts of the process are still steroid dependent.

In this study, low levels of estradiol, $6.5 \mathrm{pmol} / \mathrm{l}$ (3.213 ), were found to be associated with a $50 \%$ increase in prepubertal growth up to PHV. The boys in our study with estradiol levels around the calculated $\mathrm{EC}_{50}$ had about 1.3 years remaining to $\mathrm{PHV}$ and the data are comparable with the results presented by Klein et al. [30] in 1996. These are the levels we find in transition from early to mid puberty (testicular volume $3-6 \mathrm{ml}$ and $8-12 \mathrm{ml}$, respectively) $[10,22]$. Close to $\mathrm{PHV}$, all the boys had estradiol levels $>9 \mathrm{pmol} / \mathrm{l}$, which is in line with the levels seen in mid puberty $[10,22]$ when PHV usually occurs [31-33]. Hence, the results of this study confirm our previous observations in the clinic regarding pubertal stages and sex steroid levels. However, the scatter of estradiol levels is wider in the prepubertal and early pubertal range in relation to growth compared to the scatter of testosterone levels. It has been suggested that the effects of local paracrine or intracrine estrogen production are more important than those of circulating estrogen in men [11, 36]. It is likely that the estradiol levels of importance for early pubertal growth in boys are not the ones we measure in the serum but those resulting from aromatization in the target tissues. There is most likely a large variation in the ability to aromatize testosterone into estradiol in early puberty in boys, which could explain the wide scatter of the measured serum estradiol levels in relation to growth seen in the present study. In contrast, serum testosterone levels show a satisfactory dose-response relationship to growth from prepuberty up to PHV. The diurnal rhythm of estradiol is not apparent in early puberty in boys, as it is in girls, and the progression of estradiol in early and mid puberty is slower compared to the increase in testosterone, probably due to the limited aromatization capacity $[22,27]$. In accordance with this, the association between testosterone and estradiol in this study was more apparent later in adolescence, closer to PHV.

Estrogen - and testosterone after aromatization into estrogen - increases growth velocity during puberty, both through direct effects at the growth plate and through stimulation of GH secretion. ER- $\alpha$ and ER- $\beta$ are expressed in the anterior pituitary and the hypothalamus $[1,37,38]$. There are also several studies supporting a direct stimulatory effect of androgens on the growth plate cartilage without aromatization into estrogens, although it is now accepted that estrogen in both sexes is the critical hor- 
mone in controlling growth plate acceleration and fusion. The nonaromatizable androgens DHT and oxandrolone accelerate growth velocity without an increase in GH secretion [39-42]. The direct effect of androgens could be a contributory factor in our finding that testosterone levels show a more stable pattern than estradiol levels in relation to growth up to PHV in boys. In the absence of estradiol action, androgens seem to be able to sustain linear growth, as in the syndromes of estrogen resistance and aromatase deficiency $[2,3]$. Patients with complete androgen insensitivity syndrome have a lower final height $(-0.6 \mathrm{SD})$ than normal men, which could be explained by the loss of the direct growth-stimulating effect of androgens at the growth plates compared to normal men [4]. In addition, in girls with Turner syndrome, oxandrolone treatment has a growth-promoting effect and results in an increased final height $[43,44]$. Furthermore, boys with familial male precocious puberty treated with an aromatase inhibitor alone do not revert to the normal growth rate, as they do with combination treatment with aromatase inhibitors and antiandrogens [45]. Consequently, androgens are of importance in skeletal growth in boys and contribute to the differences in height between the sexes.

ER- $\alpha$, ER- $\beta$ and androgen receptor can be detected in the human growth plate throughout pubertal development with no sex difference [46] and it is tempting to conclude that the same levels of estradiol in the growth plate would be needed for the pubertal growth spurt in both sexes. However, the levels of serum estradiol in boys during early puberty up to $\mathrm{PHV}$ are lower compared to estradiol in girls during their growth spurt $[8,10,11]$. The levels of estradiol close to PHV seen in this study ( $>9$ $\mathrm{pmol} / \mathrm{l}$ ) are the levels we find in the transition from $\mathrm{B} 1$ to B2 in girls [27], when their pubertal growth spurt usually starts. The calculated $\mathrm{EC}_{50}$ of $17 \beta$-estradiol in this study is also lower than the corresponding $\mathrm{EC}_{50}$ in healthy girls published recently, showing a $50 \%$ increase in growth velocity from prepuberty to $\mathrm{PHV}$ at a morning $17 \beta$-estradiol level of $20 \mathrm{pmol} / \mathrm{l}$ (13-31) [47]. The important levels of estradiol at the growth plates probably correlate to serum estradiol levels to a higher degree in girls than in boys.

Although the study group in the present study includes boys with short, normal and tall stature, it is possible to analyze the boys as one study group using the pubertal growth ratio, which adjusts for their prepubertal growth. Furthermore, there is no indication of differences in testosterone levels between boys with short, normal or tall stature during puberty [15] and we believe that the calcu- lated $\mathrm{EC}_{50 \text { s }}$ provide an accurate indication of what is true regarding all pubertal boys.

In summary, this study presents the first data on the levels of testosterone and estradiol associated with increased growth up to PHV in boys. Given the limited and variable aromatization capacity in early puberty and the impact of paracrine and intracrine production of estradiol on growth, serum estradiol level is difficult to interpret in relation to growth in boys. Hence, testosterone should be the preferred sex steroid to be measured in serum when it comes to assessing increased growth during puberty up to PHV in boys. Our conclusion is that, at the start of pubertal hormone replacement therapy, the doses of testosterone used should result in the range of serum testosterone levels seen in early puberty in order to optimize the effect of testosterone on growth. This needs to be tested in future clinical studies. Nevertheless, the association we found between testosterone levels and the early part of the pubertal growth spurt is an indication that this could be the case.

\section{Acknowledgments}

The authors thank Professor Kerstin Albertsson-Wikland for making available her study group of healthy boys and for initiating the work for the present analysis. We also thank Tillväxtlaboratoriet, especially Carina Ankarberg-Lindgren, $\mathrm{PhD}$, for her skills in laboratory quality assurance. We are grateful to the staff of the GPCRC at the Queen Silvia Children's Hospital in Gothenburg, Sweden for technical support and for taking care of the children. We also wish to thank Aimon Niklasson, $\mathrm{MD}, \mathrm{PhD}$, for valuable help with programming SAS for the growth velocity calculations. This work was supported by grants from The Sahlgrenska Academy at the University of Gothenburg, the Swedish Medical Research Council (No. 7509), Thelma Zoega's foundation, Stig and Ragna Gorthon's foundation and an unrestricted research grant from Pfizer AB and IPSEN.

\section{Disclosure Statement}

A.-K.A. received an unrestricted research grant from IPSEN. E.N. declares no competing interests.

References

Albin/Norjavaara
Perry RJ, Farquharson C, Ahmed SF: The role of sex steroids in controlling pubertal growth. Clin Endocrinol (Oxf) 2008;68:4-15.

2 Morishima A, Grumbach MM, Simpson ER, Fisher C, Qin K: Aromatase deficiency in male and female siblings caused by a novel mutation and the physiological role of estrogens. J Clin Endocrinol Metab 1995;80:36893698. 
- 3 Smith EP, Boyd J, Frank GR, Takahashi H, Cohen RM, Specker B, Williams TC, Lubahn DB, Korach KS: Estrogen resistance caused by a mutation in the estrogen-receptor gene in a man. N Engl J Med 1994;331: 1056-1061.

-4 Zachmann M, Prader A, Sobel EH, Crigler JF Jr, Ritzen EM, Atares M, Ferrandez A: Pubertal growth in patients with androgen insensitivity: indirect evidence for the importance of estrogens in pubertal growth of girls. J Pediatr 1986;108:694-697.

5 Veldhuis JD, Metzger DL, Martha PM Jr, Mauras N, Kerrigan JR, Keenan B, Rogol AD, Pincus SM: Estrogen and testosterone, but not a nonaromatizable androgen, direct network integration of the hypothalamo-somatotrope (growth hormone)-insulin-like growth factor 1 axis in the human: evidence from pubertal pathophysiology and sex-steroid hormone replacement. J Clin Endocrinol Metab 1997;82: 3414-3420.

-6 Marshall WA, Tanner JM: Variations in pattern of pubertal changes in girls. Arch Dis Child 1969;44:291-303.

7 Marshall WA, Tanner JM: Variations in the pattern of pubertal changes in boys. Arch Dis Child 1970;45:13-23.

8 Klein KO, Baron J, Colli MJ, McDonnell DP, Cutler GB Jr: Estrogen levels in childhood determined by an ultrasensitive recombinant cell bioassay. J Clin Invest 1994;94:24752480.

-9 Courant F, Aksglaede L, Antignac JP, Monteau F, Sorensen K, Andersson AM, Skakkebaek NE, Juul A, Bizec BL: Assessment of circulating sex steroid levels in prepubertal and pubertal boys and girls by a novel ultrasensitive gas chromatography-tandem mass spectrometry method. J Clin Endocrinol Metab 2010;95:82-92.

-10 Janfaza M, Sherman TI, Larmore KA, BrownDawson J, Klein KO: Estradiol levels and secretory dynamics in normal girls and boys as determined by an ultrasensitive bioassay: a 10-year experience. J Pediatr Endocrinol Metab 2006;19:901-909.

$\checkmark 11$ Grumbach MM: Estrogen, bone, growth and sex: a sea change in conventional wisdom. J Pediatr Endocrinol Metab 2000;13(suppl 6):1439-1455.

12 Albertsson-Wikland K, Rosberg S, Lannering B, Dunkel L, Selstam G, Norjavaara E: Twenty-four-hour profiles of luteinizing hormone, follicle-stimulating hormone, testosterone, and estradiol levels: a semilongitudinal study throughout puberty in healthy boys. J Clin Endocrinol Metab 1997;82:541549.

13 Andersson AM, Juul A, Petersen JH, Muller J, Groome NP, Skakkebaek NE: Serum inhibin B in healthy pubertal and adolescent boys: relation to age, stage of puberty, and follicle-stimulating hormone, luteinizing hormone, testosterone, and estradiol levels. J Clin Endocrinol Metab 1997;82:39763981.
14 Mitamura R, Yano K, Suzuki N, Ito Y, Makita Y, Okuno A: Diurnal rhythms of luteinizing hormone, follicle-stimulating hormone, and testosterone secretion before the onset of male puberty. J Clin Endocrinol Metab 1999; 84:29-37.

15 Ankarberg-Lindgren C, Norjavaara E: Changes of diurnal rhythm and levels of total and free testosterone secretion from pre- to late puberty in boys: testis size of $3 \mathrm{ml}$ is a transition stage to puberty. Eur J Endocrinol 2004; 151:747-757.

16 Boyar RM, Rosenfeld RS, Kapen S, Finkelstein JW, Roffwarg HP, Weitzman ED, Hellman L: Human puberty. Simultaneous augmented secretion of luteinizing hormone and testosterone during sleep. J Clin Invest 1974;54: 609-618.

17 Norjavaara E, Ankarberg-Lindgren C: Modified Spectria testosterone RIA detects same testosterone levels in prepubertal and pubertal children as liquid chromatography tandem mass spectrometry (abstract). Horm Res 2011;76(suppl 2):750.

18 Bay K, Andersson AM, Skakkebaek NE: Estradiol levels in prepubertal boys and girls analytical challenges. Int J Androl 2004;27: 266-273.

9 Lee JS, Ettinger B, Stanczyk FZ, Vittinghoff E, Hanes V, Cauley JA, Chandler W, Settlage J, Beattie MS, Folkerd E, Dowsett M, Grady D, Cummings SR: Comparison of methods to measure low serum estradiol levels in postmenopausal women. J Clin Endocrinol Metab 2006;91:3791-3797.

20 Ankarberg-Lindgren C, Norjavaara E: A purification step prior to commercial sensitive immunoassay is necessary to achieve clinical usefulness when quantifying serum $17 \beta$-estradiol in prepubertal children. Eur J Endocrinol 2008;158:117-124.

21 Stanczyk FZ, Cho MM, Endres DB, Morrison JL, Patel S, Paulson RJ: Limitations of direct estradiol and testosterone immunoassay kits. Steroids 2003;68:1173-1178.

22 Ankarberg-Lindgren C, Norjavaara E: Twenty-four hour secretion pattern of serum estradiol in healthy prepubertal and pubertal boys as determined by a validated ultra-sensitive extraction RIA. BMC Endocr Disord 2008;8:10.

23 Wikland KA, Luo ZC, Niklasson A, Karlberg $\mathrm{J}$ : Swedish population-based longitudinal reference values from birth to 18 years of age for height, weight and head circumference. Acta Paediatr 2002;91:739-754.

24 Tanner JM: Growth at Adolescence. Oxford, Blackwell Scientific, 1962.

25 Prader A: Testicular size: assessment and clinical importance. Triangle 1966;7:240-243.

26 Tanner J, Whitehouse R, Cameron N, Marshall W, Healy M, Goldstein H: Assessment of Skeletal Maturity and Prediction of Adult Height (TW2 method). New York, Academic press, 1983.
27 Norjavaara E, Ankarberg C, Albertsson-Wikland K: Diurnal rhythm of $17 \beta$-estradiol secretion throughout pubertal development in healthy girls: evaluation by a sensitive radioimmunoassay. J Clin Endocrinol Metab 1996; 81:4095-4102.

28 Bland JM, Altman DG: Statistical methods for assessing agreement between two methods of clinical measurement. Lancet 1986;1: 307-310.

29 Liu YX, Wikland KA, Karlberg J: New reference for the age at childhood onset of growth and secular trend in the timing of puberty in Swedish. Acta Paediatr 2000;89: 637-643.

30 Klein KO, Martha PM Jr, Blizzard RM, Herbst T, Rogol AD: A longitudinal assessment of hormonal and physical alterations during normal puberty in boys. II. Estrogen levels as determined by an ultrasensitive bioassay. J Clin Endocrinol Metab 1996;81: 3203-3207.

31 Zachmann M, Prader A, Kind HP, Hafliger H, Budliger $\mathrm{H}$ : Testicular volume during adolescence. Cross-sectional and longitudinal studies. Helv Paediatr Acta 1974;29:61-72.

- 32 Tanner JM, Whitehouse RH: Clinical longitudinal standards for height, weight, height velocity, weight velocity, and stages of puberty. Arch Dis Child 1976;51:170-179.

- 33 Taranger J, Engstrom I, Lichtenstein H, Svennberg-Redegren I: VI. Somatic pubertal development. Acta Paediatr Scand Suppl 1976;258: 121-135.

-34 Albertsson-Wikland K, Rosberg S, Karlberg J, Groth T: Analysis of 24-hour growth hormone profiles in healthy boys and girls of normal stature: relation to puberty. J Clin Endocrinol Metab 1994;78:1195-1201.

-35 Weise M, De-Levi S, Barnes KM, Gafni RI, Abad V, Baron J: Effects of estrogen on growth plate senescence and epiphyseal fusion. Proc Natl Acad Sci USA 2001;98:6871-6876

-36 Simpson ER, Clyne C, Rubin G, Boon WC, Robertson K, Britt K, Speed C, Jones M: Aromatase - a brief overview. Annu Rev Physiol 2002;64:93-127.

-37 Emons J, Chagin AS, Savendahl L, Karperien M, Wit JM: Mechanisms of growth plate maturation and epiphyseal fusion. Horm Res Paediatr 2011;75:383-391.

38 Frank GR: Role of estrogen and androgen in pubertal skeletal physiology. Med Pediatr Oncol 2003;41:217-221.

39 Malhotra A, Poon E, Tse WY, Pringle PJ, Hindmarsh PC, Brook CG: The effects of oxandrolone on the growth hormone and gonadal axes in boys with constitutional delay of growth and puberty. Clin Endocrinol (Oxf) 1993;38:393-398.

40 Crowne EC, Wallace WH, Moore C, Mitchell R, Robertson WH, Holly JM, Shalet SM: Effect of low dose oxandrolone and testosterone treatment on the pituitary-testicular and GH axes in boys with constitutional delay of growth and puberty. Clin Endocrinol (Oxf) 1997;46:209-216. 
41 Keenan BS, Richards GE, Ponder SW, Dallas JS, Nagamani M, Smith ER: Androgen-stimulated pubertal growth: the effects of testosterone and dihydrotestosterone on growth hormone and insulin-like growth factor-1 in the treatment of short stature and delayed puberty. J Clin Endocrinol Metab 1993;76:9961001.

42 Eakman GD, Dallas JS, Ponder SW, Keenan BS: The effects of testosterone and dihydrotestosterone on hypothalamic regulation of growth hormone secretion. J Clin Endocrinol Metab 1996;81:1217-1223.
43 Nilsson KO, Albertsson-Wikland K, Alm J, Aronson S, Gustafsson J, Hagenas L, Hager A, Ivarsson SA, Karlberg J, Kristrom B, Marcus C, Moell C, Ritzén EM, Tuvemo T, Wattsgard C, Westgren U, Westphal O, Aman J: Improved final height in girls with Turner's syndrome treated with growth hormone and oxandrolone. J Clin Endocrinol Metab 1996; 81:635-640.

44 Menke LA, Sas TC, de Muinck Keizer-Schrama SM, Zandwijken GR, de Ridder MA, Odink RJ, Jansen M, Delemarre-van de Waal HA, Stokvis-Brantsma WH, Waelkens JJ, Westerlaken C, Reeser HM, van Trotsenburg AS, Gevers EF, van Buuren S, Dejonckere PH, Hokken-Koelega AC, Otten BJ, Wit JM: Efficacy and safety of oxandrolone in growth hormone-treated girls with Turner syndrome. J Clin Endocrinol Metab 2010;95:1151-1160.
5 Laue L, Kenigsberg D, Pescovitz OH, Hench KD, Barnes KM, Loriaux DL, Cutler GB Jr: Treatment of familial male precocious puberty with spironolactone and testolactone. $\mathrm{N}$ Engl J Med 1989;320:496-502.

46 Nilsson O, Chrysis D, Pajulo O, Boman A, Holst M, Rubinstein J, Ritzén EM, Savendahl L: Localization of estrogen receptors- $\alpha$ and $-\beta$ and androgen receptor in the human growth plate at different pubertal stages. J Endocrinol 2003;177:319-326.

47 Albin AK, Niklasson A, Westgren U, Norjavaara $\mathrm{E}$ : Estradiol and pubertal growth in girls. Horm Res Paediatr 2012;78:218-225. 